\title{
Tropical cyclone hazards and warning and disaster mitigation systems in India
}

\author{
PORATHUR V JOSEPH
}

Satellite Township, Kakanad, Cochin 682030, India

\begin{abstract}
The main features of a cyclone that cause death and destruction are: (1) Storm surge, a rapid increase in sea level along the coast, primarily caused by the strong surface wind field of the cyclone as it aṕproaches the coast, (2) the violent sustained wind and wind gusts and cyclonespawned tornadoes, and (3) the heavy rain and consequent flooding. The paper describes the structure of a tropical cyclone of hurricane intensity and its damage potential, cyclone detection, tracking, forecasting and warning systems. It concludes that with over a hundred years of research and operational experience on cyclones available with the meteorological community and with the INSAT and cyclone detection radar network, India has now an efficient cyclone warning system. This system would however benefit from further sophistication notably the use of Doppler Radars for cyclone wind field monitoring and an aircraft reconnaissance facility for probing cyclones. Research is needed to develop techniques for better forecasting of the tracks of cyclones more than a day ahead and also their intensity changes.

Cyclone disaster mitigation arrangements were organised in the maritime states of India only during the last 25 years. This relatively young field requires more developmental work, particularly in coastal area planning to reduce property losses, and exploration of alternative approaches to large-scale evacuation of the coastal population threatened by cyclones to distant temporary shelters.
\end{abstract}

Keywords. Hurricane intensity; $T$-number; eye and wall cloud; cyclone alert and warnings; cyclone disaster (distress) mitigation.

\section{Introduction}

It was Henry Piddington, President of the Marine Courts, Calcutta who pioneered scientific studies on tropical cyclones in the Indian seas, systematically collecting meteorological logs of ships plying in those waters. He published a series of memoirs in the Journal of the Asiatic Society of Bengal during 1838-1858 dealing with individual cyclones. He also wrote a book entitled The Sailor's Horn-Book for the Law of Storms, the fourth edition of which appeared in 1864.

One of the oldest recorded cyclonic storms that caused heavy casualties in India 
was the one that hit the mouth of the Ganges near Calcutta on October 7, 1737. It is reported to have killed $3,00,000$ people and destroyed 20,000 crafts of various descriptions, although there are some doubts about these figures. The river rose by 40 feet over its usual level. These details are taken from a catalogue of 112 recorded cyclones in the Bay of Bengal, up to the end of 1876 , compiled by Henry F Blanford, Meteorological Reporter to the Government of India and published in the Journal of the Asiatic Society of Bengal. In recent times, the cyclone that crossed the Andhra coast on 19 November 1977 took a toll of 10,000 lives, mainly caused by the 5-metre high storm surge that accompanied it.

Following a devastating cyclone that struck Calcutta in October 1864, the then Government of India established a cyclone-warning system for the port of Calcutta. The India Meteorological Department was born in 1875 and cyclone warning for ports, coastal areas and ships in the Indian seas became one of its routine activities. In 1969 the Government of India advised the governments of all maritime states to set up 'Cyclone Distress Mitigation Committees' (CDMC) in their respective states to effect suitable measures for mitigating the attendant hazards. An efficient, full-fledged system of cyclone 'alerts' and 'warning' has since developed in the country to cope with this recurrent natural threat.

A Tropical Cyclone Programme (TCP) was established by the World Meteorological Organisation (WMO) in 1971 to assist vulnerable countries in minimising the loss of life and property caused by these storms. For disaster prevention and preparedness measures, the TCP takes cooperative action with the office of the United Nations Disaster Relief Coordinator (UNDRO) and the League of Red Cross and Red Crescent Societies (LRCS). Five different bodies look after the regional components of the TCP. One such is the WMO/ESCAP Panel on Tropical Cyclones serving the countries bordering the Arabian Sea, the Bay of Bengal and the northern Indian Ocean. They are: Bangladesh, India, Maldives, Myanmar, Pakistan, Sri Lanka and Thailand. This panel coordinates the cooperative activities among the member countries in tackling cyclone problems. Under a Cyclone Operational Plan for the region, New Delhi issues 'Tropical Weather Outlook' daily at 0600 UTC and 'Cyclone Advisory Bulletins' at 6-hour intervals to the member countries, whenever a cyclonic storm develops in the northern Indian Ocean.

\section{Tropical cyclone and the associated hazards}

A typical mature tropical cyclone is a warm core vortex in the atmosphere (anticlockwise vortex rotation in the northern hemisphere and clockwise in the southern), cyclonic in the lower troposphere and anti-cyclonic in the upper troposphere. The circulation extends horizontally to some 1000 kilometres from the centre and vertically to about $15 \mathrm{~km}$ above sea level. There is an 'eye' at the centre of the cyclone of radius 5 to 50 kilometres. The eye is rain-free with light winds. It is surrounded by a 'wall cloud' made up of tall cumulo-nimbus clouds rising upto an altitude of $15-18 \mathrm{~km}$, the wall cloud thickness being about $10-15 \mathrm{~km}$ radially. Below the wall cloud are found the strongest surface winds of the cyclone $\left(V_{\max }\right)$ and its heaviest rain intensity. Beyond the wall cloud, surface wind speeds decrease gradually with the radial distance from the centre and rainfall is confined to the regions covered by the inward spiralling cloud-bands (composed of cumulo-nimbus clouds and some cumulus clouds at large 
distances from the centre) that are seen within a radial distance of about $400 \mathrm{~km}$ from the centre of the cyclone.

As one moves from the periphery to the centre of the cyclone, the sea level atmospheric pressure falls continuously, the largest radial pressure gradients of $2-4 \mathrm{hPa} / \mathrm{km}$ occurring in the wall cloud region. Under the influence of frictional forces, the low-level wind direction which is almost tangential to the nearly circular isobars of the cyclone field at about $1 \mathrm{~km}$ above sea level, swerves to about $25^{\circ}$ towards low pressure at sea level. The low level winds rich in moisture thus possess strong tangential and radial components causing the air parcels to spiral inwards from the peripheral regions of the cyclone towards its centre. In consequence, their rotational velocity (tangential wind) increases rapidly due to partial conservation of its angular momentum. The radial component of the wind converges large amounts of moisture to the central regions of the cyclone, which ascends and condenses in cloud formations there, keeping the central regions warmer than the surrounding tropical atmosphere. This warm anomaly which reaches a maximum of about $15^{\circ} \mathrm{C}$ at $300-200 \mathrm{hPa}$ level $(9-12 \mathrm{~km}$ altitude) reduces the radial pressure gradients at these high altitudes. The cyclonically rotating air parcels rising up in the central regions of the cyclone move outwards in the upper troposphere, under the action of unbalanced centrifugal forces (with reduced pressure gradients) and conserving angular momentum, begin to reverse their cyclonic rotation as they move further away from the centre. Satellite pictures of tropical cyclones indeed show both the inward spiralling low-level clouds and the outward-moving cirrus clouds at the upper levels.

Our current knowledge of the structure of tropical cyclones has come from studies made for over a hundred years of different cyclone-prone regions of the world. Early studies using ship reports and measurements from coastal and island observatories gave a reasonably good picture of the surface level features of the cyclone, but that of their three-dimensional structure has been derived mainly from 'reconnaissance flights' using specially equipped aircraft that were flown into the cyclone at various levels, measuring winds, temperatures, humidity and pressure. Direct sensing as well as remote sensing methods, especially compositing of data from routine balloon soundings of the atmosphere has also yielded a wealth of information (Gray 1979, pp 155-218). Details regarding the eye, wall cloud and the spiral cloud bands were obtained from satellite pictures (polar orbiting and geo-stationary) as well as cyclone detection radar systems installed at coastal and island stations. Figure 1 shows the cloud picture of a hurricane intensity tropical cyclone recorded by the cyclone detection radar at Madras.

Low pressure systems such as the tropical cyclones that occur over the oceans are classified in intensity or strength according to the highest sustained surface wind speeds (averaged over a few minutes) and not the instantaneous gust speeds of their circulations. The classification used in India is given in table 1. According to this, a low pressure vortex with winds of $64 \mathrm{knots}(32 \mathrm{~m} / \mathrm{s}$ or $115 \mathrm{~km} / \mathrm{h})$ and more is called a severe cyclonic storm with a core of hurricane winds. Similar systems are called 'hurricanes' in the Atlantic and the eastern Pacific and 'typhoons' in the western Pacific Ocean.

By comparing characteristics of the central cloud areas and the eye and spiral cloud bands of a cyclone abstracted from satellite cloud pictures with reconnaissance aircraft measurements of $V_{\max }$, Dvorak (1975) suggested a method of estimating the intensity of a tropical cyclone on a T-number scale of 1 to 8. Each T-number has a 


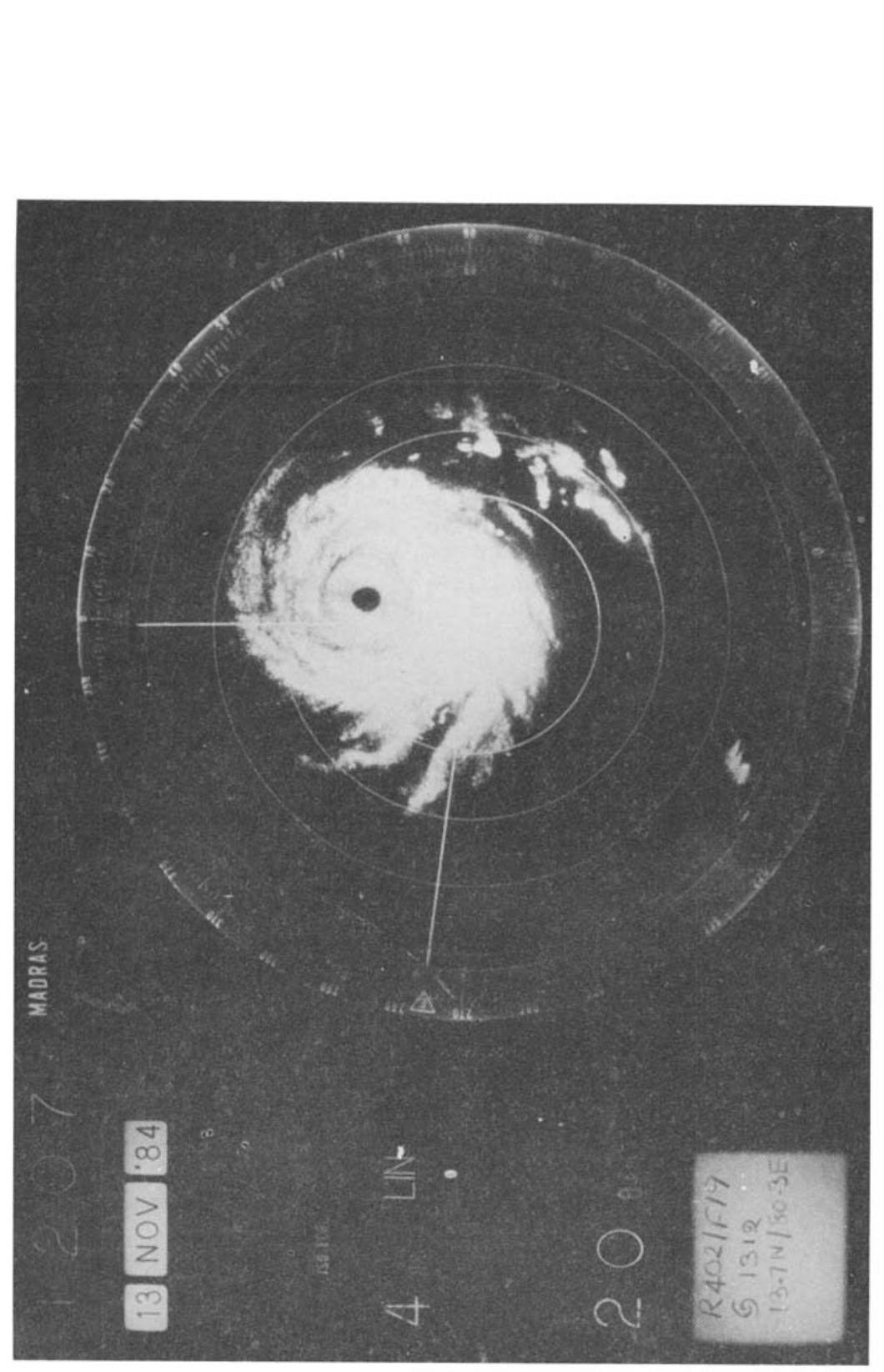

덩들

$\equiv$

บ:

5 离

요

$=\stackrel{5}{\Xi} \overline{0}$

क क

奇哭

西焉

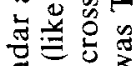

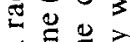

흐응 흥

융웡원

过

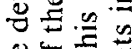

相:

흥 क्ष

겅

\&

$\exists$ 일

긍으원

可

훈

8 क

$\Xi$

气

을

군

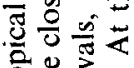

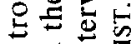

긍ㅇㅇ

त

든

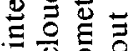

를 음

留类

证

至

㺼

ㄴ.

这谣

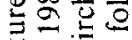

造志 丞悉

응 晋

.

- $\bar{E}$

는 0

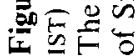


Table 1. Classification of low pressure systems in India.

\begin{tabular}{lc}
\hline Type of low pressure system & $\begin{array}{c}\text { Highest sustained surface wind } \\
\text { (speed, knots) in the circulation }\end{array}$ \\
\hline Low & $\begin{array}{l}\text { Less than } 17 \\
\text { Depression }\end{array}$ \\
$\begin{array}{l}\text { Deep depression } \\
\text { Cyclonic storm }\end{array}$ & 28 to 33 \\
Severe cyclonic storm & 34 to 47 \\
Severe cyclonic storm with a & 48 to 63 \\
$\quad$ core of hurricane winds & 64 and above \\
\hline
\end{tabular}

corresponding $V_{\max }$. About $70^{\circ}$ of the cyclones studied by Dvorak (1975) in both the Atlantic and Pacific Oceans have been shown to grow in intensity at the rate of one T-number per day.

In their mature stages, tropical cyclones the world over show great similarities in their structure and organisation. These similarities result from the strong physical forces associated with the release of latent heat and the relatively uniform characteristics of the lower boundary, i.e. the sea surface (Anthes 1982). The T-number scale developed from studies of cyclones elsewhere in the tropics, is also used in this country for determining the intensity of tropical cyclones in the Indian seas, although it would be desirable to design a T-scale specific to Indian cyclones by combining cloud picture information derived from INSAT with data systematically generated from reconnaissance flights. For, although Indian Ocean cyclones are similar in many respects to hurricanes and typhoons, they are smaller in horizontal extent than their counterparts in the Atlantic and the Pacific.

$V_{\max }$ (in knots) of a tropical cyclone has been found to be related to the pressure drop (PD) in $\mathrm{hPa}$ (the difference between the pressures at the periphery and the centre of a cyclone) by a relation of the form $V_{\max }=k(\mathrm{PD})^{1 / 2}$, where $k$ is a constant for a given ocean basin. For cyclones of the Indian seas, Mishra \& Gupta (1976) have derived the value of $k$ to be $14 \cdot 2$. The relationship between T-number, $V_{\max }$ and PD applicable to the cyclones of the Indian seas (after Dvorak 1975 and Mishra \& Gupta 1976) is given in table 2 . In Indian seas T-7 is the maximum intensity so far observed, the corresponding $V_{\max }$ being about 140 knots. The Andhra cyclone of November 1977 , for example reached an intensity of T-7 on maturity on November 18, and maintained that strength till it crossed the coast on the following day. Higher intensities of T-8 have been attained by cyclones in the Pacific and the Atlantic Oceans.

During the 100-year period 1891-1990, there have been 561 cyclones in the Indian seas with maximum winds of 34 knots or more. About $23 \%$ of these, according to the India Meteorological Department, intensified into hurricane strength attaining maximum winds of $64 \mathrm{knots}$ or more, the corresponding $\mathrm{T}$-number being 4 and PD equal to $21 \mathrm{hPa}$ (table 2). Of a sample of 181 cyclones which crossed the Indian coast north of $15^{\circ} \mathrm{N}$ during the 90-year period 1891-1980 analysed by the author and coworkers (Joseph et al 1981) only $19(10.5 \%)$ attained an intensity of T-5 ( $V_{\max }$ 90 knots and PD $40 \mathrm{hPa}$ ) and two reached intensities of T-6 and T-7 respectively.

Cyclones over the Indian seas generally form between latitudes $5^{\circ} \mathrm{N}$ and $18^{\circ} \mathrm{N}$ during the pre-monsoon (April, May and early part of June) and post-monsoon (late September to December) seasons. During the monsoon period June to September, 
Table 2. Relationship between $T$-number, $V_{\max }$ and pressure drop of a tropical cyclone in the Indian Seas (after Dvorak 1975 and Mishra \& Gupta 1976).

\begin{tabular}{lcc}
\hline T-number & $\begin{array}{c}\text { Maximum wind } \\
V_{\max }(\text { knots })\end{array}$ & $\begin{array}{c}\text { Pressure drop } \\
\text { PD (hPa) }\end{array}$ \\
\hline 1 & 25 & - \\
2 & 30 & - \\
$2 \cdot 5$ & 35 & 6 \\
3 & 45 & 10 \\
$3 \cdot 5$ & 55 & 15 \\
4 & 65 & 21 \\
$4 \cdot 5$ & 77 & 29 \\
5 & 90 & 40 \\
$5 \cdot 5$ & 102 & 52 \\
6 & 115 & 66 \\
$6 \cdot 5$ & 127 & 80 \\
7 & 140 & 97 \\
$7 \cdot 5$ & 155 & 119 \\
8 & 170 & 143 \\
\hline
\end{tabular}

weaker systems (mostly depressions) form over the northern part of the Bay of Bengal (north of $18^{\circ} \mathrm{N}$ ) and then move West-North-Westwards across North India shedding copious rainfall along their paths. This is also the period when a large number of intense hurricanes and typhoons form over the northern hemisphere Atlantic and Pacific Oceans. The occurrence of land to the north of the Indian Ocean and the large vertical shear of the wind in the monsoon atmosphere prevents intensification of these depressions into intense cyclones.

Some of the low pressure areas forming over the warm waters of the Arabian Sea and the Bay of Bengal slowly deepen into depressions. Those of them which further intensify become cyclonic storms within about two days. Some of these further intensify and develop an eye over the next few days, surrounded by a wall cloud and tightly wound spiral cloud bands with windspeeds $V_{\max }$ of 64 knots or higher and hurricane force winds extending to $50 \mathrm{~km}$ or even $100 \mathrm{~km}$ from the centre. As the Arabian Sea and the Bay of Bengal are comparatively small in area and bounded by land on three sides, many Indian cyclones encounter the coast (land-fall) early enough and thereby weaken even whilst they are in the stage of intensification. For, tropical cyclones weaken rapidly after their centre (the eye) crosses the coast primarily due to the absence of the energy laden moisture source below. This partly accounts for the low number of T-6 and T-7 cyclones in the Indian seas.

Decadal frequency of tropical cyclones ( $V_{\max } 34 \mathrm{knots}$ or more) in the Arabian Sea and the Bay of Bengal during the 100-year period 1891-1990 is shown in table 3. The moving ten-year totals of these storms are given in figure 2. Cyclone frequency (decadal) had a minimum around 1950; and maxima around 1928 and 1970 . Currently we seem to be passing through an epoch of minimum cyclone frequency. It is notable that the observed decadal frequency variation between the late 1960 s and the late 1980 s by a factor of two belongs to the era of satellite monitoring, when no cyclone was missed. What then could be the cause of this large variation in cyclone frequency? And will an era of high cyclone frequency return in the future and, if so, when? 
Table 3. Decadal frequency of tropical cyclones in the Arabian Sea and the Bay of Bengal (data provided by Dr G S Mandal).

\begin{tabular}{lc}
\hline Decade & $\begin{array}{c}\text { Number of cyclonic storms } \\
\left(V_{\max } 34 \text { knots and more }\right)\end{array}$ \\
\hline $1891-1900$ & 58 \\
$1901-1910$ & 58 \\
$1911-1920$ & 52 \\
$1921-1930$ & 67 \\
$1931-1940$ & 61 \\
$1941-1950$ & 51 \\
$1951-1960$ & 41 \\
$1961-1970$ & 63 \\
$1971-1980$ & 64 \\
\hline $981-1990$ & 38 \\
\hline
\end{tabular}

Studies at the Colorado State University on the spatial distribution of the frequency of tropical cyclones during the 20-year period 1958-1977 (Gray 1979) have shown that the climatological cyclone genesis depends on several parameters such as sea surface temperature (SST) and the depth of warm water (ocean thermal energy above the level of $26^{\circ} \mathrm{C}$ in the top 60 metres of the ocean), the vertical shear between horizontal winds at 950 and $200 \mathrm{hPa}$, middle tropospheric relative humidity, cyclonic vorticity in the low level air flow and the degree of convective instability in the atmosphere that is necessary for the formation of cumulo-nimbus clouds without which tropical cyclones cannot develop. Some of these parameters may be responsible for the observed decadal variability. An indepth study of this problem may create insights for forecasting active and weak epochs of cyclone frequency, several years in advance. Landsea (1993) has reported that intense hurricanes over the Atlantic Ocean during the 1970 s and 1980 s were much less frequent than those experienced during the 1950 s and 1960 s.

On an average, about 80 tropical cyclones with sustained winds of $20-25 \mathrm{~m} / \mathrm{s}$ (40-50 knots) occur each year in the seven cyclone prone ocean basins (Gray 1979).

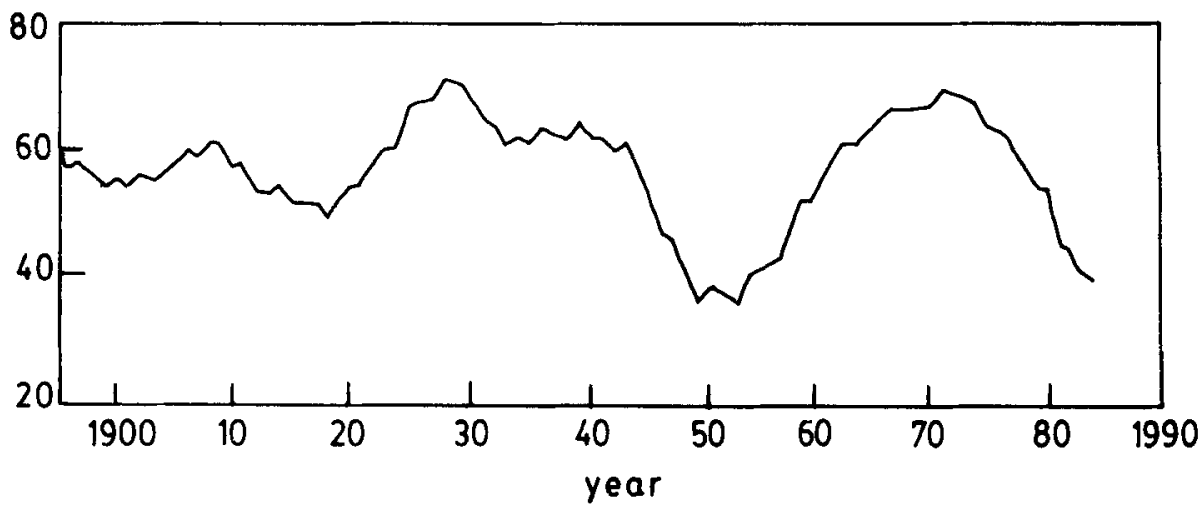

Figure 2. Ten-year moving totals of number of cyclonic storms in the Arabian Sea and the Bay of Bengal with $V_{\max }=34$ knots or more during the period 1891-1989. The figure was provided by $\mathrm{Dr}$ G S Mandal. 


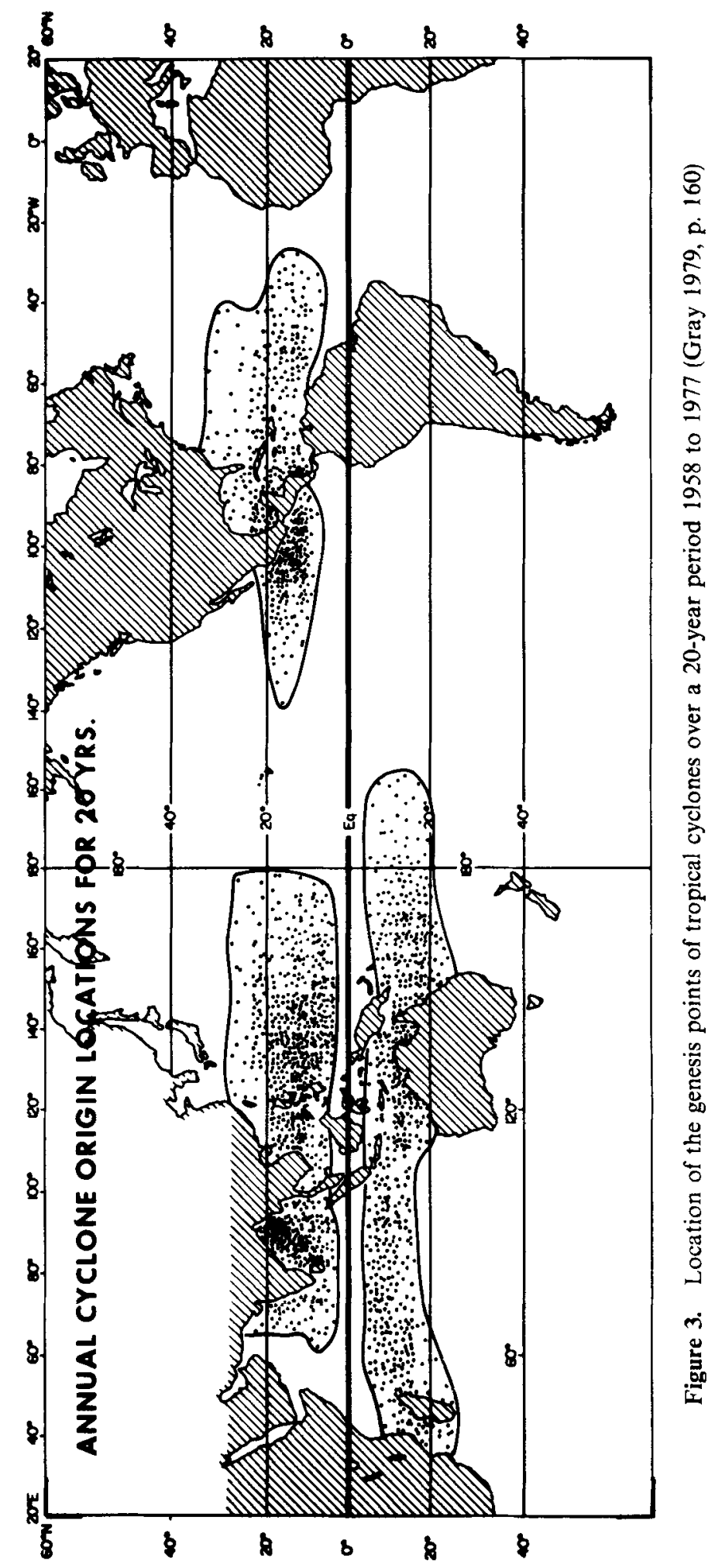


Table 4. Annual frequency of tropical cyclones by ocean basin-average of 20 years 1958 to 1977 (Gray 1979. pp. 155-218).

\begin{tabular}{cccccccc}
\hline $\begin{array}{c}\text { North } \\
\text { Indian }\end{array}$ & $\begin{array}{c}\text { Northwest } \\
\text { Pacific }\end{array}$ & $\begin{array}{c}\text { Northeast } \\
\text { Pacific }\end{array}$ & $\begin{array}{c}\text { Northwest } \\
\text { Atlantic }\end{array}$ & $\begin{array}{c}\text { South } \\
\text { Indian }\end{array}$ & Australian & $\begin{array}{c}\text { Southwest } \\
\text { Pacific }\end{array}$ & Total \\
\hline 6.4 & $26 \cdot 3$ & 13.4 & 8.8 & 8.4 & $10 \cdot 3$ & 5.9 & 79.5 \\
\hline
\end{tabular}

Figure 3 shows the location of the genesis points of these cyclones for the 20 -year period 1958-1977; the ocean basin-wise frequency is given in table 4. Tropical cyclones are completely absent in the cold ocean waters of the South Atlantic and the eastern South Pacific, nor do they form within $4-5^{\circ}$ latitude of the equator. The western Arabian Sea does not produce tropical cyclones either. Nearly $65 \%$ of the global tropical cyclones form in the zone bounded by $10^{\circ}$ and $20^{\circ}$ latitude.

In a survey of the period 1964-1978 (Southern 1979), it was found that cyclones caused maximum deaths when compared to other natural disasters (table 5). In November 1970 a single cyclone took a toll of 3,00,000 lives in Bangladesh. Over the years, as methods for forecasting the track and intensity of cyclones have improved, disaster mitigation efforts have made remarkable progress, greatly reducing the death toll, although damage to property has steadily increased due to unplanned expansion of human habitats and activities in coastal areas subject to cyclone threats. Figure 4 shows the potential major impacts of a tropical cyclone upon landfall. The important factors are: (1) storm surge, that is, a sudden rise in sea level along the coast, primarily caused by strong surface winds of the cyclone as it approaches the coast, (ii) strong sustained wind, wind gusts and tornadoes and (iii) heavy rain which in many cases is of the order of 30-50 centimetres per day over large areas. In addition to the loss of human and animal lives, damage to structures and destruction of crops as shown in the figure, there are attendant dislocations like loss of communication and power,

Table 5. Natural disasters (1964-1978).

\begin{tabular}{|c|c|c|}
\hline Disaster & $\begin{array}{l}\text { Total deaths } \\
\text { in } 14 \text { years }\end{array}$ & Greatest single event \\
\hline Tropical cyclones & 416972 & $\begin{array}{c}300000 \\
\text { (Bangladesh, 1970) }\end{array}$ \\
\hline Earthquakes and tidal waves & 195328 & $\begin{array}{c}66794 \\
\text { (Peru, 1969) }\end{array}$ \\
\hline Floods & 26724 & $\begin{array}{c}8000 \\
\text { (S. Vietnam, 1964) }\end{array}$ \\
\hline Tornadoes, severe local storms & 4062 & $\begin{array}{c}540 \\
\text { (Bangladesh, 1969) }\end{array}$ \\
\hline Avalanches and landslides & 5790 & $\begin{array}{c}1450 \\
\text { (Peru, 1974) }\end{array}$ \\
\hline Volcanic eruptions & 2572 & $\begin{array}{c}2000 \\
\text { (Zaire, 1973) }\end{array}$ \\
\hline Extratropical cyclones & 1860 & $\begin{array}{c}166 \\
\text { (USA, 1966) }\end{array}$ \\
\hline Heat (cold) waves & 505 & $\begin{array}{c}291 \\
\text { (India, 1973) }\end{array}$ \\
\hline
\end{tabular}

Compiled from Encyclopaedia Britannica by Southern (1979) 


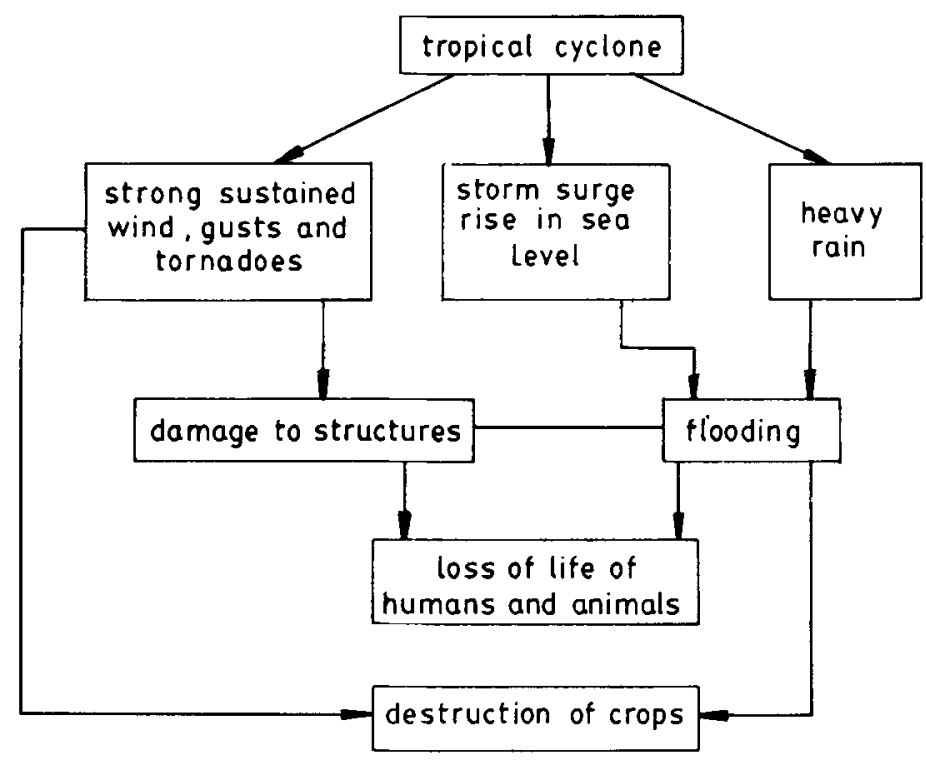

Figure 4. The potential major impacts of a tropical cyclone upon crossing the coast (landfall).

the erosion of beaches, damage to off-shore installations, damage to shipping and fishing, loss of soil fertility due to saline incursion, and contamination of domestic water supply (Anthes 1982; Southern 1987).

\section{The cyclone warning system}

The India Meteorological Department is the agency responsible for monitoring cyclone development in the Indian seas and for the issue of timely alerts and warnings regarding their temporal evolution and associated weather hazards. It functions through the Area Cyclone Warning Centres (ACWC) at Bombay, Calcutta and Madras, and the Cyclone Warning Centres (CWC) at Ahmedabad, Bhubaneshwar and Vishakhaptnam. With the routine availability of hourly cloud pictures now, taken by the Indian geostationary satellite INSAT (visible during day light hours and infra-red round the clock) the problem of timely detection of tropical cyclones that generally form far out in the sea, and of following their tracks has been largely solved. Ten high power cyclone detection radars along the east and west coasts of India are capable of seeing the eye, wall cloud and the spiral cloud bands of a cyclone out to $400 \mathrm{~km}$ away from the coast (about the distance covered by a cyclone in a day). The Cyclone Detection Radar (CDR) network of India is shown in figure 5. Adjacent radar stations have overlapping range circles so that the same cyclone can be seen by more than one station at any time when they are close to the coast. With INSAT and the CDR we now have a dependable system for cyclone warning. Radar systems and satellites employ remote sensing techniques. It has been reported however that errors in determining the cyclone centre can be up to $110 \mathrm{~km}$ by satellite fixes, $20-55 \mathrm{~km}$ by radar observations and about $20 \mathrm{~km}$ by aircraft reconnaissance (Elsberry 1987, pp. 1-12, 91-131). Additional data required come from meteorological measurements 


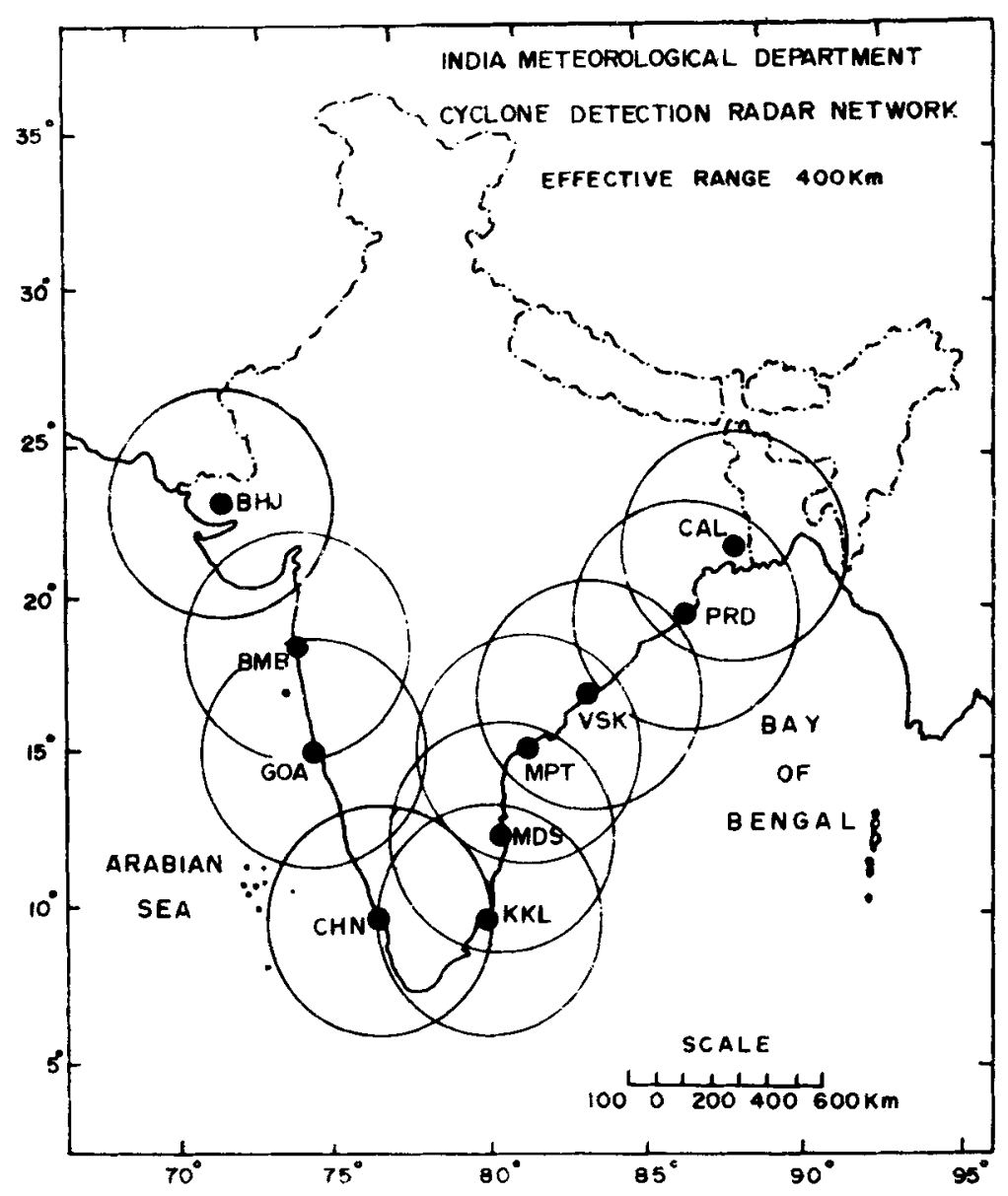

Figure 5. The cyclone radar network along the Indian coast line.

taken by coastal and island observatories and from ships in the field of the cyclone whose data routinely flow into the cyclone warning centres. What we do not have is a reconnaissance aircraft facility. These specially instrumented aircraft provide accurate information about the location of the cyclone centre and other details regarding its intensity and the spatial distribution of winds. Such a facility used to be provided by the Department of Defence (DOD) of USA for the collection of data from hurricanes in the Atlantic and typhoons in the Pacific, but was discontinued for the North-West Pacific in August 1987. Gray et al (1991) studied the technical aspects of this issue at the instance of the American Meteorological Society and found that although weather satellites are absolutely essential for tropical cyclone observation, satellite measurements of position, intensity, ambient wind distribution etc. of a cyclone are sometimes degraded leading to inaccuracy in forecasts. Additional data from reconnaissance flights can offset this drawback.

Doppler radars have capabilities to provide details of the cyclone's wind field in addition to usual data on the eye, wall cloud and spiral cloud bands produced by conventional radars. Their ability to continuously monitor the wind maxima associated with the wall cloud and the radial extent of the hurricane strength wind field can be 
of great assistance to the forecaster. The United States has planned to deploy Doppler radars round the country during the 1990s (WMO 1990). The India Meteorological Department too, it is understood, has plans to replace the existing CDR network with Doppler radars in a phased manner.

The most important element to be forecast is the future path or track of a cyclone. Where will it cross the coast is also very important. Many of the Indian cyclones move Westwards and North-Westwards. Their tracks are easier to forecast. Others while moving initially in these directions, later turn Northwards. Some of them turn East of North; these are the 'recurving' cyclones and forecasting their track is a difficult problem, often involving large errors.

Objective schemes have been developed for forecasting cyclone tracks, based on persistence, climatology and steering. A persistence forecast uses a linear extrapolation of the smoothed observed track of the cyclone during the previous 12 or 24 hours. The climatological forecast moves the cyclone in the resultant direction with the average speed of movement of all the past cyclones over a 50 to 100 -year period in a small area around its present location and a small calendar time interval (say one or two weeks) on either side of that day. An objective method combining both these approaches called CLIPER is in wide use today. India also uses this seheme in operational cyclone warning and advisories are issued to forecasters from a central office. The large scale atmospheric flow in which the tropical cyclone is embedded is empirically related to the cyclone track. This phenomenon is called 'steering', and is derived routinely from the twice-daily balloon soundings of the atmosphere from a large network of radiosonde stations world-wide and from cloud motion vectors obtained from geo-stationary satellites like INSAT. The steering concept is very useful in cyclone-track prediction, particularly to forecast recurvature.

Forecasters can also get guidance from statistical-dynamical models in which the cyclone motion is statistically related to the large scale atmospheric flow features, actually observed or forecast. For cyclone forecasting beyond a day, one also needs an accurate prediction of changes in the large scale circulation around the cyclone. The National Centre for Medium Range Weather Forecast (NCMWRF) established at New Delhi with a super-computer facility can greatly empower the cylone forecaster in this endeavour by forecasting the evolution of the large scale atmospheric flow around India a few days ahead.

Forecasting intensity changes of cyclones is another area where empiricism prevails. While cyclones continue to intensify (many at one T-number per day) over the warm seas, and reach maturity at some $T$-number, what may be the environmental factors in the atmosphere and oceans that determine the maximum intensity of a cyclone and its growth rate prior to reaching that intensity? This is an area of intense current research. For a 12 - or 24 -hour advance prediction of intensity changes, persistence forecasts are usually quite good.

However, all over the world today the final or official cyclone forecast, although aided by objective advisories like CLIPER or the output from a statistical-dynamical model, is a subjective decision where the skill and experience of the forecaster is most important. Fully deterministic prediction of cyclone intensity and movement, beginning from accurate initial data on the cyclone and its large-scale environment, using appropriate models and fast computers, is a goal being pursued in some centres of research, but its use in cyclone warning may be decades away in the future.

Errors (the distance between a forecast position and that subsequently occupied by the cyclone centre) in the forecasts prepared at the National Hurricane Center, 
USA for the decade $1982-1991$ averaged 100,193 and $383 \mathrm{~km}$ respectively for $12-, 24-$ and 48-hour advance forecasts respectively (AMS 1993). All users of cyclone warnings should be aware of the current accuracy levels in forecasting cyclone tracks.

\section{Cyclone disaster mitigation}

The cyclone distress mitigation committees constituted in the coastal states of India since 1969 have made steady progress in disaster mitigation efforts. A good example of its functioning may be seen from the action taken during a recent severe cyclone that crossed the Andhra coast on May 9, 1990. The feeble system that originated over the South-West Bay of Bengal intensified into a cyclonic storm by 1730 IST (Indian Standard Time) of May 5, 1990. It attained hurricane intensity on the morning of May 6 when its centre was $450 \mathrm{~km}$ South-East of Madras. Moving North-West it was located $300 \mathrm{~km}$ South-East of Madras on the morning of May 7. Moving further in a northerly direction it crossed the South Andhra coast near the mouth of the river Krishna (south of Machilipatnam) at about 1900 IST on May 9, 1990 and weakened.

The system was continuously tracked by INSAT-1B all through its life. It attained a peak intensity of 6.5 on the T-number scale on the morning of May 8 . The system slightly weakened to T-5.5 before crossing the coast. After the cyclone came into radar range it was tracked by the cyclone detection radars at Karaikal, Madras and Machilipatnam during the period May 7 to 9.

The following information is extracted from a report on the cyclone prepared by the Andhra Pradesh State Government. On receipt of the first message regarding the cyclone by the government agencies (Chief Secretary, Collectors etc.) on-May 5, a central Control Room (manned by representatives from revenue, police, army and telecommunication departments) was immediately activated. Subsequently, 28 more bulletins were received at the Control Room from the Meteorological Department. The Chief Minister of the State constantly reviewed the situation from May 6 onwards. A high-level meeting of cabinet ministers, senior secretaries to government and heads of departments was called by the Chief Minister on May 8 to review the action being taken. The cyclone control room was equipped with a police wireless system and HAM sets to maintain communication in the event of failure of normal communication links which generally get disrupted in a cyclonic storm situation. The assistance of voluntary agencies was sought. A high-level Natural Calamity Coordination meeting was also convened with the officers of the armed forces to formulate relief and rescue measures. In an exercise of an unprecedented nature, 6,51,865 persons from 546 villages were evacuated to safer places and sheltered in 1098 relief centres for 3 to 8 days. The cyclone took a toll of 967 lives. But for the timely large-scale evacuation of people, the loss of life would have been colossal, as the storm surge associated with the cyclone, raised the sea level by four metres above the normal tide level (Subramanian and Mohanan 1992).

Cyclone distress mitigation has several components, but I would like to highlight (i) long-term measures, and (ii) measures to be adojpted during a period of cyclone threat. Long-term measures include the construction of cyclone shelters to which humans and animals could be transported at short notice, the continuing education of officials and the public regarding cyclone hazards and the available warning and disaster mitigation systems, the periodic review of cyclone-warning terminology to 
make the warnings easily and unambiguously understood by the public, and lastly coastal area planning to reduce property damage by cyclones. In all these areas except the last India has made notable advances.

According to expert opinion (Southern 1987, pp. 147-185) there are four ingredients necessary for implementing an effective system of long-term mitigation planning for coastal areas: (i) a technical evaluation of the climatological risk posed by cyclones and cyclonic effects in selected coastal sectors (Joseph et al 1981 is an attempt in that direction, prepared in connection with the planning stage for the establishment of a major steel mill near Paradeep); (ii) an assessment of the relative vulnerability of populations within these selected boundaries to the cyclonic effects of stated intensity or strength; (iii) The establishment of structural design codes, regulatory controls and minimum safety standards within an authoritative framework of legislation designed to encourage public adherence; and (iv) educational programmes to gain community acceptance of the costs of cyclone disaster mitigation.

Finally, in addition to the alerts, warnings and other advisory bulletins to the officials as per the CDMC plans, the public should be kept periodically informed about the progress of the cyclone, through all available media channels. The chief of the tropical cyclone warning centre should make a personal appearance on television, particularly at critical times during the approach of a cyclone so as to infuse confidence in the assessment made of the threat. Latest cyclone pictures taken by the radar network may be shown on such occasions to support the confidence in warnings. The public should be educated about the basic features, such as the appearance of a sudden lull in the wind as the eye of the storm passes over the station, to be followed by strong winds from an opposite direction about half an hour to an hour later. The public should also be advised not to heed rumours and to carefully listen to official bulletins over the radio and television and cooperate with the officials who act on directions from the Control Room which is in live contact with the related Area Cyclone Warning Centre.

\section{Conclusions}

India has now a fairly dependable and efficient cyclone warning system, comparable to those in USA and Australia.

The following suggestions for further improvement may be useful.

- Techniques for measurement of the low level wind field of the cyclone may be improved. Specifically,

(a) Robust wind instruments may be deployed along our coast that can withstand the fury of the cyclone and make accurate measurements up to at least 180 knots.

(b) The plan to replace the existing cyclone detection radars with Doppler radars may be expedited. In addition to monitoring the low level wind field, a Doppler radar can detect tornadoes in the field of cyclones. We have at present very little information on the occurrence of tornadoes in the Indian cyclones.

(c) Reconnaissance aircraft facility may be added to this system. It is suggested that we may begin with just two such aircraft (one in an operation mode and the other as a standby). Measurements made during these flights can greatly enhance the reliability of data obtained from satellites for inference of cyclone parameters including wind. Reconnaissance aircraft reports of cyclone location and intensity 
are considered to be the most reliable. This facility can also be used for research on tropical cyclones.

- Quantitative information on rainfall rates can be derived from radar reflectivity mappings. When combined with digitally telemetered rain guage reports, quantitative estimates of the rainfall in the cyclone field can be made. Radar provides a spatial and time resolution that cannot be achieved by a rainguage network. This is useful for assessing in real time, the potential flooding situations in association with cyclone rainfall (Elsberry 1987, pp. 1-12, 91-131). It would be prudent to develop this capability in India.

- Development of statistical-dynamical models linking cyclone motions with the observed large-scale atmospheric flow fields can help in forecasting cyclone motion up to 3 days in advance. But to accomplish this we have to develop capabilities for numerical prediction of the flow field for the same period. We have the potential to achieve this capability at the National Centre for Medium Range Weather Forecasting.

- Overwarning of our coastal areas in routine cyclone warning is common. The severe weather of a cyclone at any given instant affects a coastal area about $100 \mathrm{~km}$ in length. Since there are errors of the order of $200 \mathrm{~km}$ in a 24-hour forecast of the cyclone track, a severe weather warning normally covers $300-500 \mathrm{~km}$ of the coast, even in the case of cyclones with smooth tracks. To be effective warnings must be given 24 hours ahead so that there is adequate time for distress mitigation efforts particularly evacuations which can only be made during daylight hours. Considerably larger lengths of the coast-line can be included for warnings and alerts, particularly in cases of erratic movement of cyclones and cyclone motion along curved coastlines, since in the case of cyclones it is better to be overwarned than underwarned or taken unawares. The excellent capabilities to detect and track cyclones and to determine their intensities make such a warning a real assessment of the threat, unlike in the case of an earthquake which strikes without notice.

- We have seen that in the recent May 1990 cyclone about six and a half lakh persons were evacuated. It was a necessary exercise under the then existing conditions to reduce loss of life, but shifting people large distances away from their homes brings untold misery to them, and it is realised that lateral evacuation to distant sites may not be the most appropriate solution. WMO has recommended development of in-situ survival strategies: Construction of adequate cyclone survival shelters suitable for vertical evacuation. With such an option, warning times could be reduced, thereby minimising overwarning (WMO 1990).

- Making available robust communication facilities at the time of cyclones is an important requirement for India. At present we have an operational Disaster Warning System (DWS) linked with INSAT which was developed and implemented in the coastal districts of Tamilnadu and Andhra Pradesh in 1987 for rapid and direct dissemination of cyclone warnings from the Area Cyclone Warning Centre at Madras to a large number of receiving stations. Raghavan \& Sen Sarma (1989) report that the system was adjudged to be quite successful on all the three occasions when cyclones struck our coasts in 1987 . There are plans to extend this facility to other states and this may be expedited. 
I thank the Indian Academy of Sciences for inviting me to contribute to the special issue of Sadhana. Thanks arc also due to Dr N Sen Roy, New Delhi, Dr G S Mandal, New Delhi, Sri S Ganesan, Madras, Sri S K Subramanian, Madras, and Sri S Raghavan, Madras for helpful discussions. The radar picture of the cyclone in figure 1 was kindly provided to the author by the India Meteorological Department, Government of India.

\section{References}

AMS 1993 Policy statement on hurricane detection, tracking and forecasting of the American Meteorological Society, as adopted by the Exeoutive Committee on 23 April 1993. Bull. Am. Meteorol. Soc. 74: 1377-1380

Anthes R A 1982 Tropical cyclones, their evolution, structure and effects. Meteorological monographs (Boston: Am. Meteorol. Soc.) vol. 19, no. 41

Dvorak V F 1975 Tropical cyclone intensity analysis and forecasting from satellite imagery. Mon. Weather Rev. 103: 420-430

Elsberry R L (ed.) 1987a Observation and analysis of tropical cyclones. A global view of tropical cyclones (Monterey, CA: Naval Postgraduate School)

Elsberry R L (ed.) 1987b Tropical cyclone motion. A global view of tropical cyclones (Monterey, CA: Naval Postgraduate School)

Gray W M 1979 Hurricanes, their formation, structure and likely role in tropical circulation. Meteorology over the tropical oceans (ed.) D B Shaw (Bracknell: R. Meteorol. Soc.)

Gray W M, Neumann C, Tsui T L 1991 Assessment of the role of aircraft reconnaissance on tropical cyclone analysis and forecasting. Bull. Am. Meteorol. Soc. 72: 1867-1883

Joseph P V, Ghosh S K, Sharma B L, Seshadri V R 1981 Report on the impact of cyclonic storm and storm surge near Paradeep. India Meteorological Department

Landsea C W 1993 A climatology of intense (or major) Atlantic hurricanes. Mon. Weather Rev. 121: 1703-1713

Mishra D K, Gupta G R 1976 Estimation of maximum wind speeds in tropical cyclones occuring in Indian seas. Indian J. Meteorol. Hydrol. Geophys. 27: 285-290

Raghavan S, Sen Sarma A K 1989 Dws- A satellite based warning system. Proceedings of the symposium on Preparedness, Mitigation and Management of Natural Disasters, pp. 4-27 to 4-30.

Southern R L 1979 The global socio-economic impact of tropical cyclones. Aust. Meteorol. Mag. 27: 175-195

Southern R L 1987 Tropical cyclone warning and mitigation systems. A global view of tropical cyclones (ed.) R L Elsberry (Monterey, CA: Naval Postgraduate School)

Subramanian S K, Mohanan G 1992 Some features of the Bay cyclone of May 1990. Vayu Mandal 22: 97-102

WMO 1990 Tropical cyclone warning systems WMO/TD No. 394, Report No. TCP-26,World Meteorological Organisation, Geneva 